\title{
Over 99.6 wt\%-pure, sub-millimeter-long carbon nanotubes realized by fluidized-bed with careful control of the catalyst and carbon feeds
}

Zhongming Chen ${ }^{a, b}$, Dong Young $\mathrm{Kim}^{b}$, Kei Hasegawa ${ }^{b}$, Toshio Osawa ${ }^{b}$, Suguru Noda ${ }^{b, *}$

${ }^{a}$ Department of Chemical System Engineering, School of Engineering, The University of Tokyo, 7-3-1 Hongo, Bunkyo-ku, Tokyo 113-8656, Japan

${ }^{b}$ Department of Applied Chemistry, School of Advanced Science and Engineering, Waseda University, 3-4-1 Okubo, Shinjuku-ku, Tokyo 169-8555, Japan

\begin{abstract}
To establish a method for sub-second conversion of acetylene to sub-millimeter-long carbon nanotubes (CNTs), we have proposed and developed an internal heat-exchange reactor for fluidized-bed chemical vapor deposition (FBCVD). This reactor enabled sufficient heating of the reaction gas and uniform heating of the bed of alumina beads at a space velocity as high as $3600 \mathrm{~h}^{-1}$. The direct feeding of the catalyst vapors (aluminum isopropoxide for the alumina support layer and ferrocene for the iron particles) to the bed separately from the other gases, which were fed through the heat-exchange and preheating zone and the distributer, enabled the careful control of the catalyst particles deposited on the beads. By decreasing the
\end{abstract}

\footnotetext{
* Corresponding author: Tel/Fax: +81-3-5286-2769.

E-mail address: noda@waseda.jp (S. Noda).
} 
acetylene feed concentration and preventing the deactivation of small Fe particles, we realized semi-continuous production of 99.6-99.8 wt\%-pure, sub-millimeter-long, few-wall CNTs with an average diameter of $6.5 \mathrm{~nm}$ at a carbon yield of $42 \%$. The FBCVD reactor with an internal heat-exchanger can be scaled-up for practical mass production with uniform and energy-saving heating. 


\section{Introduction}

Carbon nanotubes (CNTs) have attracted a lot of attention owing to their unique one-dimensional nanostructure and extraordinary electrical, thermal, mechanical, and optical properties. Their ability to form self-organized conductive networks as well as their large specific surface area, high chemical/mechanical stability, and light weight make them an attractive candidate for electrodes of batteries, capacitors, and solar cell devices [1-6]. The low-cost production of carbon nanotubes (CNTs) will open many opportunities for their practical application. Different methods have been used to produce high-quality CNTs, including electric arc discharge [7,8], laser vaporization [9], chemical vapor deposition (CVD) [10-12], and plasma-enhanced CVD [13]. Among these methods, CVD is one of the most commonly used techniques for laboratory- and commercial-scale controllable growth of CNTs $[14,15]$. Fluidized-bed CVD (FBCVD) is one of the most popular ways for the mass production of CNTs because of advantages in terms of providing sufficient surface area for supporting catalysts and growing CNTs, excellent mass and heat transfer, easy scale-up, and continuous operation [14-20]. Single-wall CNTs (SWCNTs) to multi-wall CNTs (MWCNTs) have been mass produced by FBCVD. However, CNTs tend to entangle with catalysts and supports and thus need post treatment, which creates additional costs and damages the CNTs.

Since the report in 1996 [21], vertically aligned (VA) CNT arrays have been a focus in CNT production because of the uniform tube length, uniform orientation, and extra high purity. Impurity-free, millimeter-long, SWCNTs have been produced by the water-assisted CVD method [22], and such synthesis is now possible using several CVD recipes on catalyst-supported flat substrates [23-26]. However, the limited surface area of the two-dimensional (2D) growth substrate is a major obstacle for the mass-production of such CNTs. To improve the productivity of CNT arrays, some researchers have chosen 
three-dimensional (3D) support materials to extend the reaction surface. Wei and coworkers used spherical ceramic beads in a thin fixed-bed and synthesized MWCNT arrays [27-29]. They also used vermiculite as a catalyst carrier and grew micrometer-tall MWCNT arrays among the layers of vermiculite via FBCVD, and realized the mass production of CNTs at 3.0 $\mathrm{kg} \mathrm{h}^{-1}$ using a pilot plant reactor with an inner diameter of $0.5 \mathrm{~m}[18,30]$.

We previously developed an original FBCVD method and realized semi-continuous production of sub-millimeter-long few-wall CNTs (FWCNTs) from acetylene $\left(\mathrm{C}_{2} \mathrm{H}_{2}\right)$ at a high carbon yield $\geq 70 \%$ and short gas residence time of $\sim 0.3 \mathrm{~s}$ [19]. The high gas feed enabled the rapid conversion of $\mathrm{C}_{2} \mathrm{H}_{2}$ to $\mathrm{CNTs}$ but caused insufficient heating of the bead bed when scaled up. In situ catalyst deposition on spherical alumina $\left(\mathrm{Al}_{2} \mathrm{O}_{3}\right)$ beads by the FBCVD enabled the semi-continuous operation of catalyst deposition, CNT growth, and CNT separation/collection. However, the catalyst vapor fed through the distributor caused stacking after $\sim 20$ cycles and resulted in an interrupted semicontinuous operation. In this study, we designed and developed a new FBCVD reactor with an internal heat-exchange and preheating zone, and investigated its performance in producing sub-millimeter-long CNTs.

\section{Experimental}

All processes for catalyst (re)deposition, catalyst reduction, CNT growth, CNT separation, and removal of residual carbon were performed in a single FBCVD reactor (Fig. 1), similar to our previous work [19] but using a new reactor tube with an internal heat-exchange and preheating zone. Commercially available $\mathrm{Al}_{2} \mathrm{O}_{3}$ beads (purity $>99.95$ wt.\%, $0.5 \mathrm{~mm}$ average diameter, and $3.89 \mathrm{~g} \mathrm{~cm}^{-3}$ density, Taimei Chemicals, Japan) were loaded in the reactor with a static bed height of $30 \mathrm{~mm}$. All of the gases except for the catalyst vapor were fed into the outer tube (inner and outer diameters of 50 and $55 \mathrm{~mm}$, respectively). 
The gas flowed down and was preheated by the furnace and the hot effluent gas in the inner tube, and then flowed into the inner tube (inner and outer diameters of 40 and $44 \mathrm{~mm}$, respectively) through the distributor at the bottom of the reactor tube. Catalyst vapors of aluminum-isopropoxide and ferrocene were fed directly into the bed through the catalyst line penetrating the distributor from the bottom, minimizing their decomposition in the catalyst line while promoting their decomposition on the "hot beads" (Fig. 1a) (see also the detailed structure in Supplementary data, Fig. S1). An $\mathrm{AlO}_{x}$ support layer was formed on the beads in 2 min by supplying aluminum isopropoxide vapor, which was sublimated in an evaporator at $130{ }^{\circ} \mathrm{C}$ and carried in 450 standard $\mathrm{cm}^{3}$ Ar gas [225 standard cubic centimeter ( $\mathrm{sccm}$ ), 3 atm for $2 \mathrm{~min}] . \mathrm{AlO}_{x}$ support layer of a few tens of nanometers in thickness is very important to activate the Fe particles, not only for the growth on flat substrates $[23,25]$ but also for the FBCVD growth on $\mathrm{Al}_{2} \mathrm{O}_{3}$ beads with sputtered catalyst [20]. We have carefully adjusted the Ar carrier gas volume to make Fe particles active and fixed it at 450 standard $\mathrm{cm}^{3}$. Then, $\mathrm{Fe}$ particles were formed on the $\mathrm{AlO}_{x}$ layer in 2 min by supplying ferrocene vapor, which was sublimated at $120^{\circ} \mathrm{C}$ and carried in 50-250 standard $\mathrm{cm}^{3}$ Ar gas $(25-125 \mathrm{sccm}, 2.2-2.5$ atm for $2 \mathrm{~min}$ ) to adjust the amount of Fe. Deposition of both $\mathrm{AlO}_{x}$ and $\mathrm{Fe}$ was performed with 4 vol\% $\mathrm{O}_{2} /$ Ar to completely decompose the vapor, and at $20 \mathrm{slm}$ to fluidize the bed well and uniformly deposit the catalyst on the beads. After reducing the deposited Fe by flowing 26 vol\% $\mathrm{H}_{2} / 0.06$ vol\% $\mathrm{H}_{2} \mathrm{O} / \mathrm{Ar}$ at $9.48 \mathrm{slm}$ for $10 \mathrm{~min}, \mathrm{CVD}$ was performed by flowing $0.37-1.1$ vol\% $\mathrm{C}_{2} \mathrm{H}_{2} / 26$ vol\% $\mathrm{H}_{2} / 0.06$ vol\% $\mathrm{H}_{2} \mathrm{O} / \mathrm{Ar}$ at 9.48 slm for $10-20 \mathrm{~min}$ (Fig. 1b). Note that, the time for catalyst deposition was separated from that for CNT growth to obtain better control of the catalyst diameter (and thus the CNTs) and to ensure the continuous growth of CNTs from the catalysts on the bead's surface [19]. The CNTs were then separated from the beads by vigorously fluidizing the bed with $\mathrm{Ar}$ gas at $20 \mathrm{slm}$ for $10 \mathrm{~min}$ (Fig. 1c). The residual carbon on the beads was removed by oxidizing with $20 \mathrm{vol} \% \mathrm{O}_{2} / \mathrm{Ar}$ at $5 \mathrm{slm}$ for $5 \mathrm{~min}$. The 
cycle was then moved to the redeposition process. Note that the $\mathrm{AlO}_{x}$ support layer was deposited every cycle to cover the coarsened Fe particles and have fresh Fe particles to maintain the small diameter of the catalyst particles and CNTs for further cycles [19]. These processes were repeated at a constant bed temperature of $745^{\circ} \mathrm{C}$ by changing the gas flow to minimize the time and energy consumed for cooling/heating the bed [19]. $\mathrm{Al}_{2} \mathrm{O}_{3}$ beads with a relatively large diameter of $0.5 \mathrm{~mm}$ were used to keep the beads in the reactor tube under a high gas flow for growth and separation of CNTs. For such big beads, the minimal fluidization velocity is about $0.1 \mathrm{~m} \mathrm{~s}^{-1}$ [19]. We kept the flow rates and thus the gas velocities high enough for all steps of catalyst deposition $\left(20 \mathrm{slm}\right.$ total flow rate and $1.0 \mathrm{~m} \mathrm{~s}^{-1}$ gas velocity), catalyst reduction $\left(9.48 \mathrm{slm}\right.$ and $\left.0.47 \mathrm{~m} \mathrm{~s}^{-1}\right)$, CNT growth $\left(9.48 \mathrm{slm}\right.$ and $\left.0.47 \mathrm{~m} \mathrm{~s}^{-1}\right)$, CNT separation (20 slm and $1.0 \mathrm{~m} \mathrm{~s}^{-1}$ ), and oxidation of the residual carbon (5 slm and 0.25 $\mathrm{m} \mathrm{s}^{-1}$ ), resulting in a slugging fluidized bed (ambient pressure for all steps). 


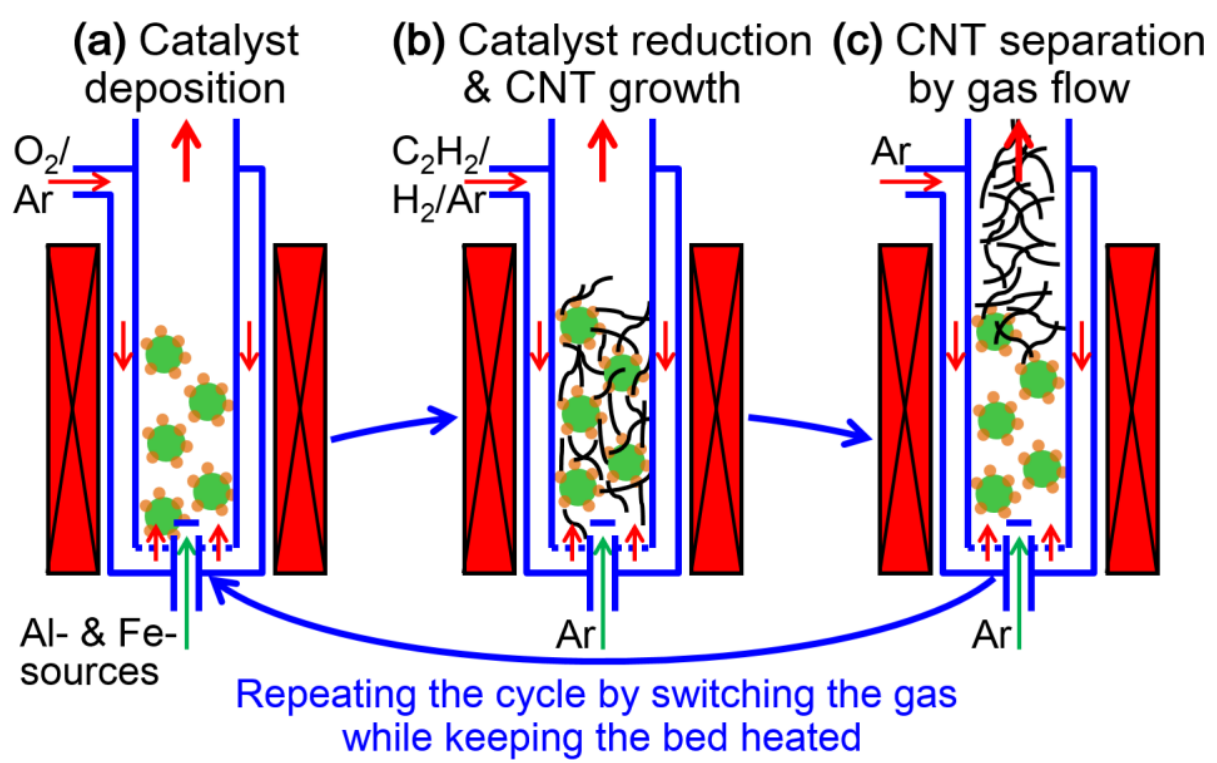

Fig. 1 - Schematics of the semi-continuous fluidized-bed process: (a) deposition of $\mathrm{AlO}_{x}$ support layer from aluminum-isopropoxide followed by deposition of Fe catalyst particles from ferrocene; (b) reduction of Fe catalyst by introducing $\mathrm{H}_{2}$ followed by $\mathrm{CNT}$ growth by feeding $\mathrm{C}_{2} \mathrm{H}_{2}$; and (c) separation of CNTs from beads by increasing Ar gas flow. After removing the residual carbon on the beads by introducing $\mathrm{O}_{2}$, the next cycle is carried out starting at step (a). The whole process can be repeated by just changing the gas flow while keeping the bed heated at a fixed temperature for tens of cycles without changing the beads.

The synthesized CNT samples were characterized by field emission scanning electron microscopy (SEM; Hitachi S-4800, Tokyo, Japan). Some VA-CNTs were transferred from the beads to copper microgrids using tweezers and observed via transmission electron microscopy (TEM; JEOL 2000EX, Akishima, Japan). The CNT powders after separation were characterized by thermogravimetric-differential thermal analysis with a ramp rate of $5{ }^{\circ} \mathrm{C}$ $\min ^{-1}$ in air (TG-DTA; Rigaku TG8120, Akishima, Japan). The Brunauer-Emmett-Teller (BET) surface areas of the CNT samples were determined by $\mathrm{N}_{2}(77 \mathrm{~K})$ volumetric adsorption (Quantachrome Instruments Autosorb 1C, Boynton Beach, FL, USA) after pre-evacuation at 
$423 \mathrm{~K}$ and $10^{-4} \mathrm{~Pa}$ for $2 \mathrm{~h}$. The CNT paper made by dispersion in ethanol and vacuum filtration was analyzed by X-ray fluorescence spectroscopy (XRF; Rigaku ZSX Primus 2, Akishima, Japan) to determine its elemental composition. The nominal thickness of the deposited Fe on the beads and the composition of the ash of the CNTs after the TG-DTA measurement were analyzed using an energy dispersive X-ray spectrometer (EDS; AMETEK EDAX Genesis, Berwyn, PA, USA) coupled with SEM. The catalysts deposited on the bead surface was analyzed by atomic force microscopy (AFM; SPM 9600; Shimadzu, Kyoto, Japan). The composition of the effluent gas from the FBCVD reactor was measured using a gas chromatograph (GC; Shimadzu GC-2014, Kyoto, Japan) equipped with a flame ionization detector.

\section{Results and discussion}

3.1 Heating state of the bed in the reactor with an internal heat-exchange and preheating zone

We first investigated and compared the heating states of the bead bed $(30 \mathrm{~mm}$ static height) using the old single tube (22 $\mathrm{mm}$ in inner diameter, Fig. 2a) and the new coaxial double tube (40 $\mathrm{mm}$ in inner diameter for the bed, Fig. 2b) using the same furnace (300 $\mathrm{mm}$ in length, the distributor set at $32 \mathrm{~mm}$ from the furnace bottom, and the thermocouple for furnace control set outside of the reactor tube at $150 \mathrm{~mm}$ from the furnace bottom) with the same set temperature of $820^{\circ} \mathrm{C}$ and various Ar flow rates. As with the old reactor tube (Fig. 2a), the top region of the bed was heated well to $830^{\circ} \mathrm{C}$ at $140 \mathrm{~mm}$ from the distributor, but the bottom of the bed was insufficiently heated $\left(690{ }^{\circ} \mathrm{C}\right)$ for an Ar flow rate of $3.16 \mathrm{slm}$. The temperature of the distributor of the reactor tube decreased to $630{ }^{\circ} \mathrm{C}$ with an Ar flow rate of $10 \mathrm{slm}$. Although fluidized beds are known to effectively enhance mass and heat transport, 
rapid gas feed with a residence time $\leq 0.3$ s causes insufficient heating. Such insufficient heating becomes more serious for larger reactor tubes. In contrast, for the new reactor tube with two feed lines (Fig. 2b), one line from the bottom directly to the bed for catalyst vapors and the other line for the other gases from the top through the heat-exchange and preheating zone and the distributor at the bottom, the temperature was more uniform. For the low total gas feed rate of $5 \mathrm{slm}$, the temperature at the distributor of the reactor tube was $750{ }^{\circ} \mathrm{C}$ because $1 \mathrm{slm}$ Ar gas was directly fed into the bed from the catalyst line without preheating. With the increase in the total gas feed, the effect of the cold Ar gas decreased, the temperature became more uniform, and the temperature at the bottom of the reactor tube increased, reaching $780{ }^{\circ} \mathrm{C}$ at a high $\mathrm{Ar}$ gas feed rate of $30 \mathrm{slm}$ (corresponding to a space velocity as high as $3600 \mathrm{~h}^{-1}$ ). It should be noted that this more uniform heating was achieved for a reactor tube with a larger diameter $(40 \mathrm{~mm})$ than the old reactor tube $(22 \mathrm{~mm})$. The uniform heating even with the cold catalyst line gas will realize the efficient control of CNT growth by FBCVD with minimal catalyst stuck in the feed line. In addition, improved heating for the increased gas feed rate suggests good compatibility with scale-up. Furthermore, the heat-exchange zone will enable the reduction of the heating power consumption by heating the cold inlet gas with the hot effluent gas. 

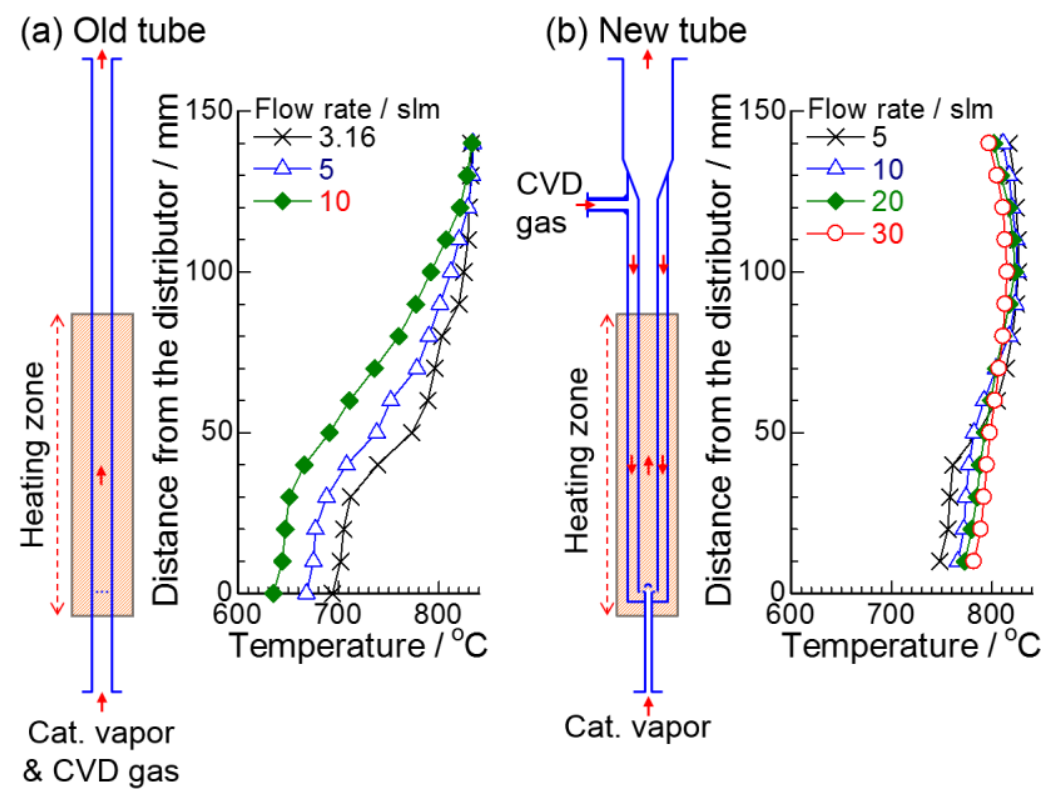

Fig. 2 - Schematics of (a) the old single tube and (b) the new coaxial double tube with temperature distributions for various Ar gas feeds. In (a), Ar gas was fed at 3.16-10 slm to the bed through the distributor at the bottom. In (b), Ar gas was fed through two inlets: constantly from the catalyst line at the bottom at $1 \mathrm{slm}$ and from the top through the heat-exchange and preheating zone and the distributor at the bottom at 4-29 slm. The inner tube diameter for the bed was $22 \mathrm{~mm}$ for (a) and $40 \mathrm{~mm}$ for (b), and the set temperature was $820^{\circ} \mathrm{C}$ for both (a) and (b).

\subsection{Semi-continuous production of CNTs and resulting CNT structure}

Photos of the fluidized-bed reactor were taken without gas flow at each step by interrupting the semi-continuous operation (Fig. 3). $82 \mathrm{~g}$ of pristine $\mathrm{Al}_{2} \mathrm{O}_{3}$ beads initially had a bed height of $3 \mathrm{~cm}$ (Fig. 3a). After depositing the $\mathrm{Fe} / \mathrm{AlO}_{x}$ catalyst on the beads and reducing them with $\mathrm{H}_{2}, \mathrm{CVD}$ was carried out for $20 \mathrm{~min}$. The bead bed remarkably increased in height (by more than four times) from 3 to $13 \mathrm{~cm}$ owing to the sub-millimeter-long CNT arrays grown on the bead surfaces (Fig. 3b). These CNT arrays were easily separated from the beads by vigorously fluidizing the beads with an increased Ar carrier gas flow and $0.82 \mathrm{~g}$ of CNTs, 
which corresponds to a carbon yield of $37 \%$ (note that $2.23 \mathrm{~g}$ carbon was fed as $1.1 \mathrm{vol} \%$ $\mathrm{C}_{2} \mathrm{H}_{2}$ in $20 \mathrm{~min}$ ), were collected in a $0.5 \mathrm{~L}$ bottle (Fig. $3 \mathrm{~d}$ ). The bead bed height decreased from 13 to around $3 \mathrm{~cm}$ (Fig. 3c), indicating rather efficient separation of CNTs from the beads. Then, the residual carbon on the beads was removed by oxidation with $\mathrm{O}_{2} / \mathrm{Ar}$ for 5 $\min$.

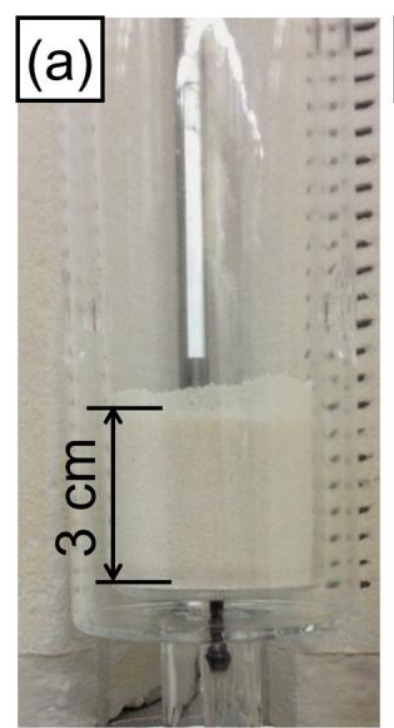

Before CVD

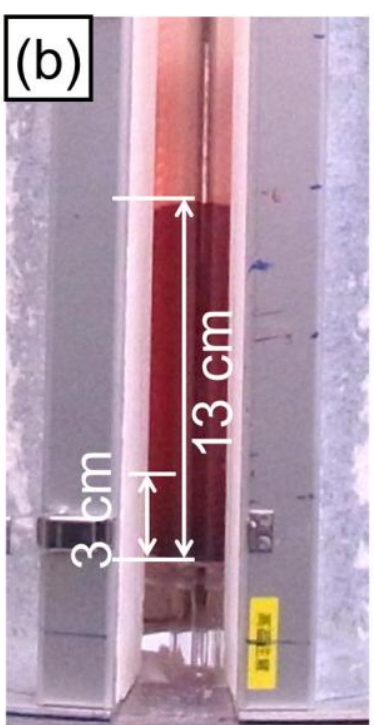

After CVD
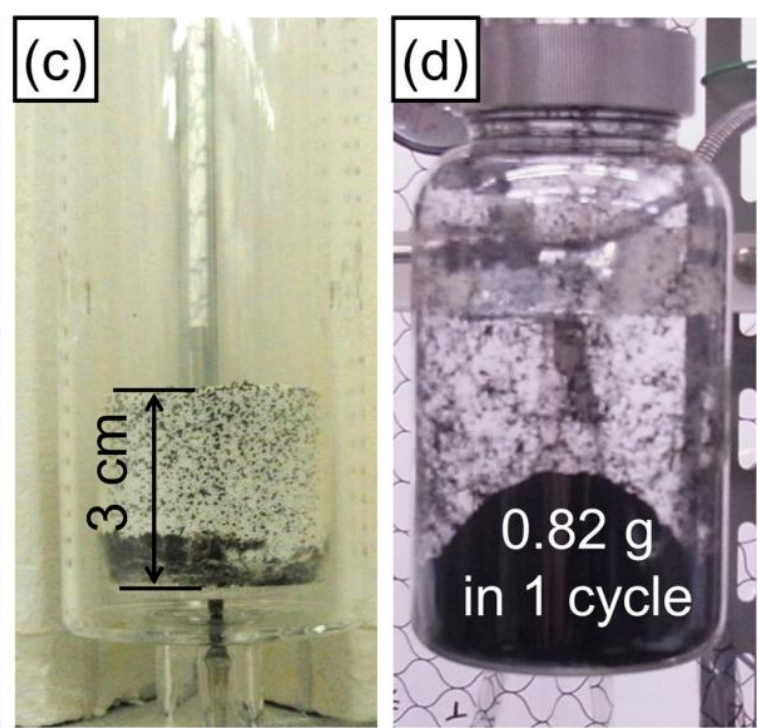

After separation Collected CNTs

Fig. 3 - Photos of the fluidized-bed reactor taken by stopping the gas flow and interrupting the cycle at each step of the semi-continuous operation: (a) the bed with pristine beads before CVD; (b) the bead bed after CVD; (c) the bead bed after CNT separation; and (d) CNTs collected in a $0.5 \mathrm{~L}$ container in one cycle. All steps were performed by gas flow modulation at a fixed set temperature of $745{ }^{\circ} \mathrm{C}$ in a single fluidized-bed reactor.

Fig. 4a,b shows the SEM images of the CNT arrays collected in the container (Fig. 3d). The CNTs were 0.3-0.4 mm long and appeared well-aligned (Fig. 4a). Note that CVD was carried out with a lower gas flow rate of $9.48 \mathrm{slm}$ than for CNT separation ( 20 slm) so that CNTs could continuously grow without separation during CVD. However, in the enlarged image in Fig. 4b, the CNT array had rather poor alignment, which is sometimes observed for 
VA-CNT arrays. Fig. 4d-f shows the TEM images of the CNTs taken near the top (Fig. 4d), middle (Fig. 4e), and bottom (Fig. 4f) of a single piece of the CNTs taken out of the array. The inset histograms of the CNT diameter distributions show that the diameter increased with increasing depth. Fig. 4c shows the average diameter of the CNTs at different depths from the top of the VA-CNTs. The diameter increased from 9.9 to $12.5 \mathrm{~nm}$ with an average diameter of $11 \mathrm{~nm}$. Because CNTs grow in root growth mode, this result indicates that the diameter of the CNTs increases with time because of gradual coarsening of the catalyst particles during CVD, which is in good agreement with the diameter increase in growing SWCNTs during rapid growth on flat substrates by CVD [25,26,31-33]. We have achieved the semi-continuous production of sub-millimeter-long CNTs using the new reactor tube with a larger cross-section than our previous method. However, the resulting CNTs had a rather disordered structure with a large diameter. Next, we carried out the experiment with careful control of the catalyst and CVD conditions. 

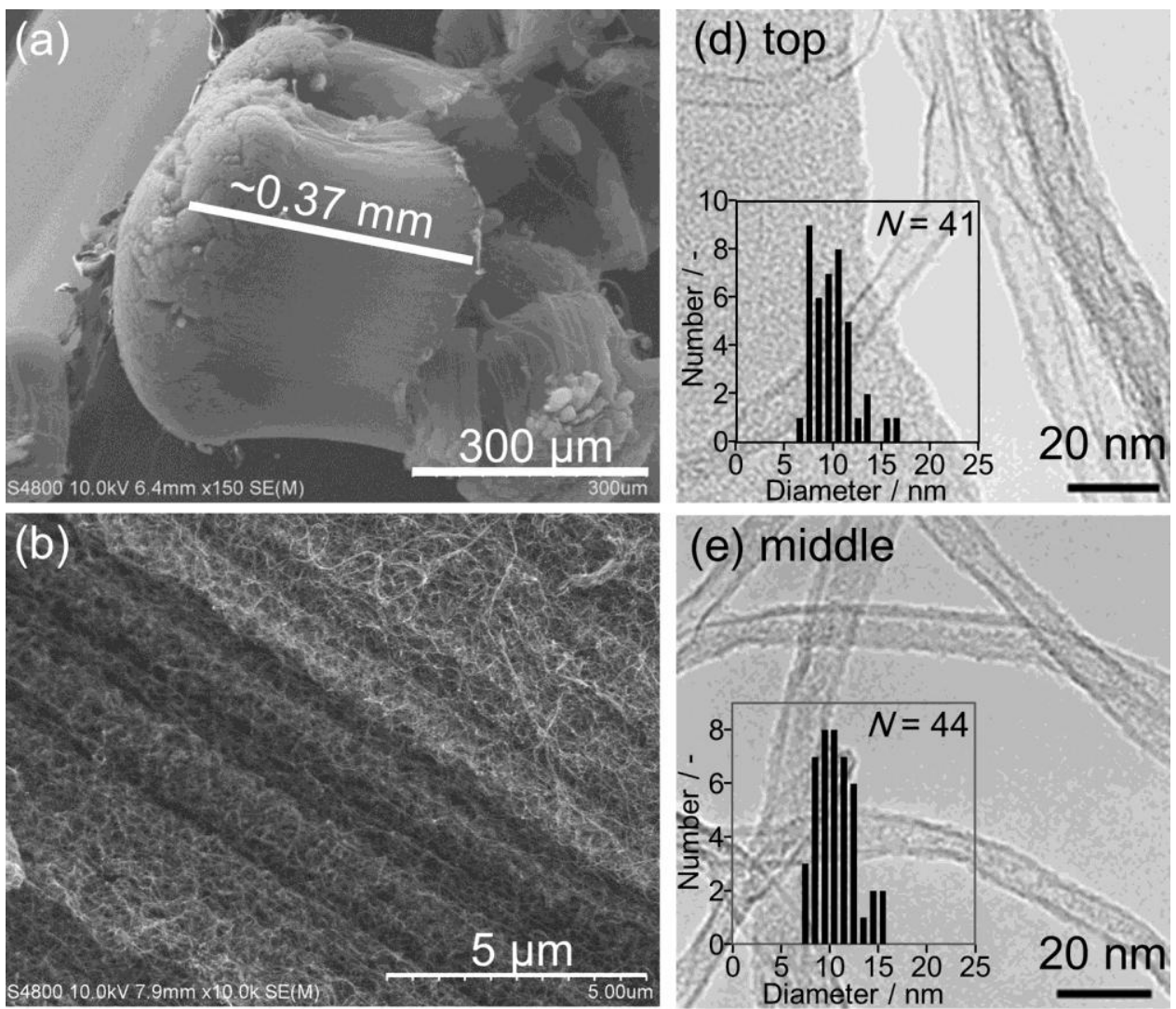

(c)
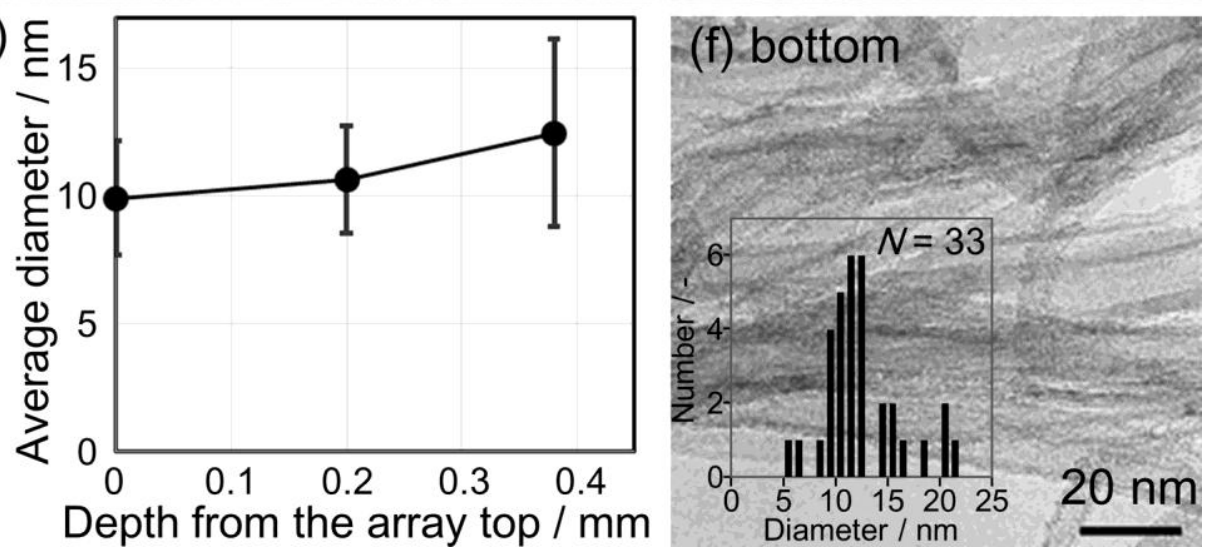

Fig. 4 - (a, b) SEM images of the CNTs separated from the beads by the gas flow and collected in the container bottle. (c) The change in the average diameter of the CNTs plotted against the depth from the top of the CNT arrays. The error bars show the standard deviation. (d-f) TEM images and diameter distributions of CNTs at the top, middle, and bottom of a single piece of the CNTs taken out from the array, respectively. 
Control of the catalyst particle size is crucially important to control the diameter of CNTs. Because the catalyst particle size can be largely controlled by the nominal thickness of the catalyst layer [24,34], we changed the Ar carrier gas volume for ferrocene and examined the structure of the resulting Fe particles by AFM.

Fig. 5a shows the nominal thickness of Fe deposited on the $\mathrm{AlO}_{x}$ layer on the $\mathrm{Al}_{2} \mathrm{O}_{3}$ beads measured by SEM-EDS. To determine the average value for different beads, three different points were measured for each bead and five beads were measured for each condition. The nominal Fe thickness was $1.77 \mathrm{~nm}$ with 250 standard $\mathrm{cm}^{3}$ Ar gas used to carry ferrocene, and it linearly decreased with Ar carrier gas volume to $0.28 \mathrm{~nm}$ with 50 standard $\mathrm{cm}^{3}$ Ar gas. Fig. $5 \mathrm{~b}-\mathrm{d}$ shows AFM images of the $\mathrm{Al}_{2} \mathrm{O}_{3}$ bead surface with $\mathrm{AlO}_{x}$ support layer (Fig. 5b) and Fe catalyst particles on the $\mathrm{AlO}_{x}$ support layer (Fig. 5c and d). The $\mathrm{AlO}_{x}$ support layer had a roughness with in-plane size of several tens of nanometers (Fig. 5b). Ferrocene carried by 250 standard $\mathrm{cm}^{3} \mathrm{Ar}$ gas formed Fe particles with around 20-40 nm diameter (Fig. 5c), while ferrocene carried by 50 standard $\mathrm{cm}^{3} \mathrm{Ar}$ gas formed smaller Fe particles with around 10-20 nm diameter (Fig. 5d). The nominal Fe thickness was in a similar range to the sputtered catalyst used to produce millimeter-tall SWCNTs on flat substrates (typically $0.5-1.0 \mathrm{~nm})[23,25,26]$. However, the number density of Fe particles was about one order of magnitude smaller $\left(10^{10-11} \mathrm{~cm}^{-2}\right)$ than the sputtered catalyst (typically $\sim 1 \times 10^{12} \mathrm{~cm}^{-2}$ [26]). The difference possibly arises from the different reactivity of the depositing Fe species: sputtered $\mathrm{Fe}$ atoms attach to both the $\mathrm{AlO}_{x}$ support layer and the nucleated $\mathrm{Fe}$ particles whereas ferrocene preferentially reacts with the nucleated Fe particles, resulting in larger $\mathrm{Fe}$ particles with smaller number density. 

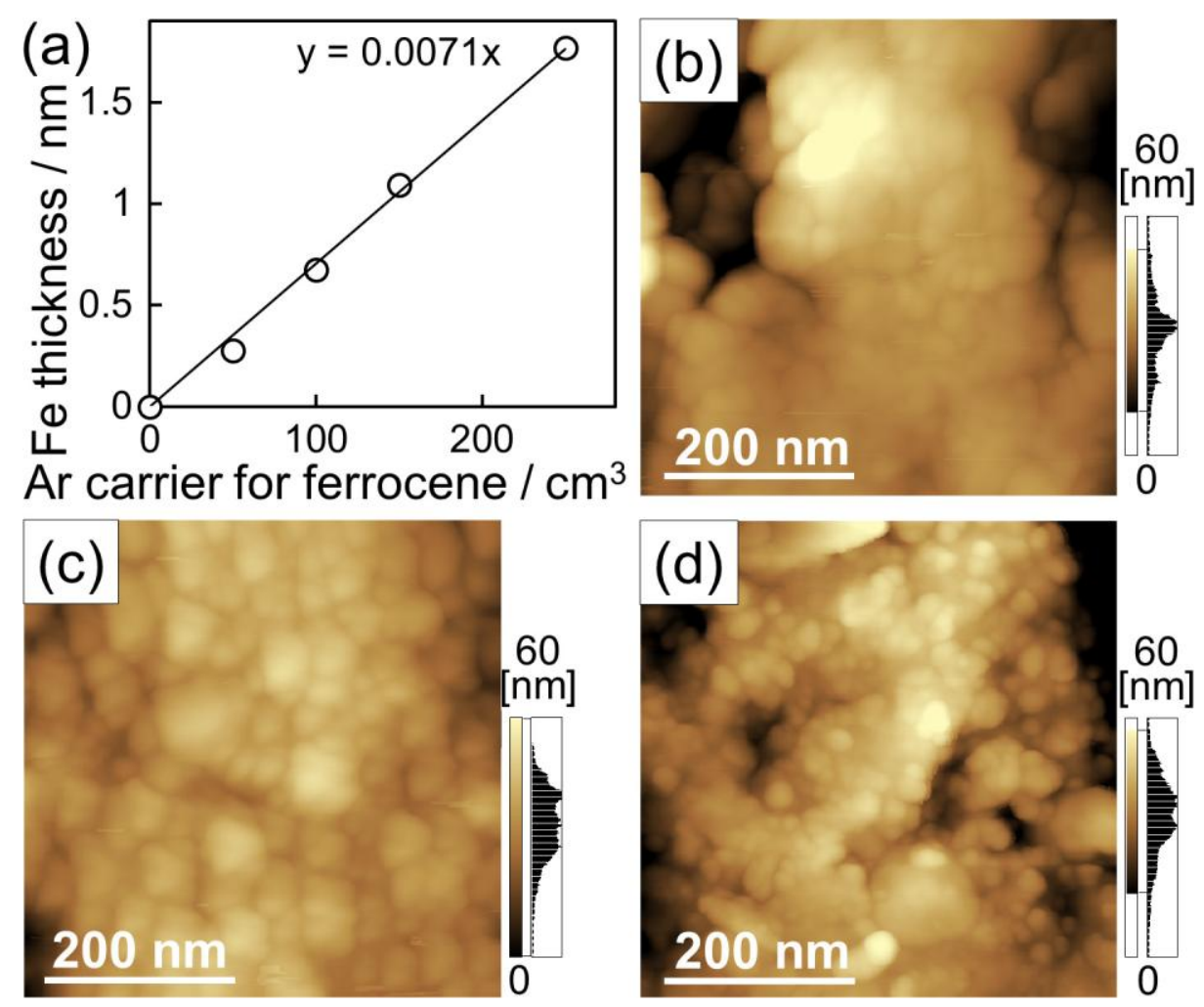

Fig. 5 - (a) Relationship between the nominal Fe thickness and the Ar carrier gas volume for ferrocene. AFM images of the alumina bead surface with different catalyst layers: (b) $\mathrm{AlO}_{x}$, (c) $1.77 \mathrm{~nm} \mathrm{Fe} \mathrm{on} \mathrm{AlO}_{x}$, and (d) $0.28 \mathrm{~nm} \mathrm{Fe}$ in $\mathrm{AlO}_{x}$. The $\mathrm{AlO}_{x}$ layer was deposited by carrying aluminum isopropoxide using 450 standard $\mathrm{cm}^{3} \mathrm{Ar}$ gas in all cases. The Fe catalyst was deposited on the $\mathrm{AlO}_{x}$ layer by carrying ferrocene using (c) 250 and (d) 50 standard $\mathrm{cm}^{3}$ Ar gas and reduced with 26 vol\% $\mathrm{H}_{2} / 0.06$ vol\% $\mathrm{H}_{2} \mathrm{O} / \mathrm{Ar}$ at $9.48 \mathrm{slm}$ for $10 \mathrm{~min}$.

Using these catalysts, we next synthesized CNTs by FBCVD under the same conditions as for Figs. 3 and 4 (i.e., 1.1 vol\% $\mathrm{C}_{2} \mathrm{H}_{2} / 26$ vol\% $\mathrm{H}_{2} / 0.06$ vol\% $\mathrm{H}_{2} \mathrm{O} / \mathrm{Ar}$ at $9.48 \mathrm{slm}$ and 745 $\left.{ }^{\circ} \mathrm{C}\right)$. Fig. 6 shows the SEM images, array lengths, and weight of the CNT arrays collected in the container bottle. From the SEM images, all of the CNTs are aligned and sub-millimeter long, even after separation by vigorous fluidization. The array lengths were longer for larger Ar carrier gas volume of ferrocene (i.e., larger Fe particles with larger nominal Fe thickness, 
Fig. 5) and for longer CVD time of 20 min (Fig. 6k). For $10 \mathrm{~min}$ CVD, the weight of CNTs collected in the container bottle was $0.4-0.5 \mathrm{~g}$ per cycle, and similar for different Fe feeds. For 20 min CVD, the weight of CNTs increased from 0.45 to $0.82 \mathrm{~g}$ per cycle with increasing Fe catalyst feed from 50 to $250 \mathrm{~cm}^{3}$. The large Fe catalyst particles formed with 250 standard $\mathrm{cm}^{3} \mathrm{Ar}$ carrier gas for ferrocene (Fig. 5c) gave a larger amount of CNTs after 20 min $(0.82 \mathrm{~g})$ than after $10 \mathrm{~min}(0.52 \mathrm{~g})$, meaning that the catalyst remained active for $20 \mathrm{~min}$. In contrast, the small Fe catalyst particles formed with 50 standard $\mathrm{cm}^{3}$ Ar carrier gas for ferrocene (Fig. 5d) gave a similar amount of CNTs after $10(0.40 \mathrm{~g})$ and $20 \mathrm{~min}(0.45 \mathrm{~g})$, meaning that this catalyst was mostly deactivated in 10 min. To produce CNTs with small diameter at a high yield, it is essential to find the conditions that keep small Fe particles active for long CVD time. 


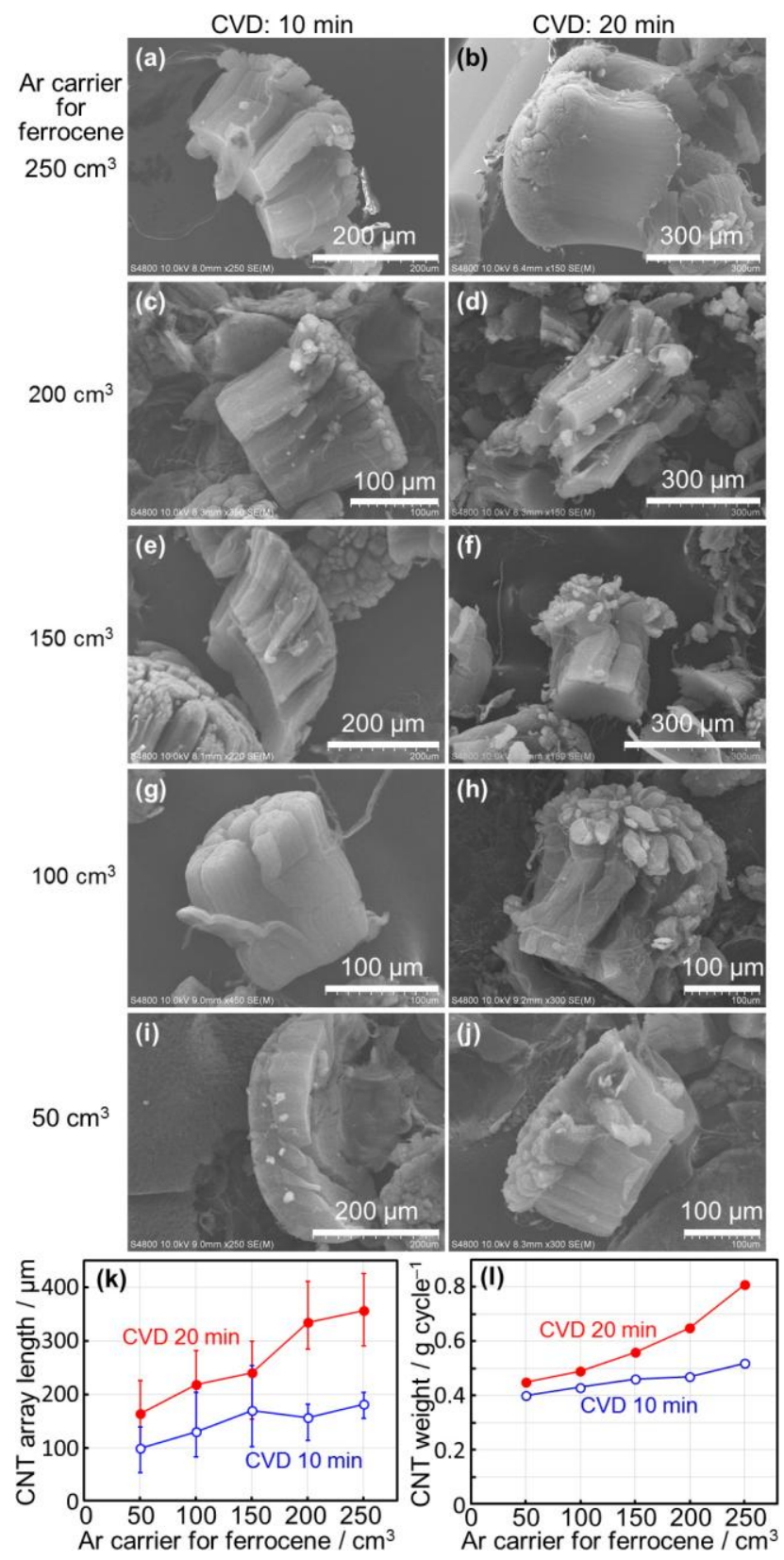

Fig. 6 - (a-j) SEM images, (k) array lengths, and (l) weight of CNT arrays collected in the container bottle. The Ar carrier gas for ferrocene was varied between 50 and 250 standard $\mathrm{cm}^{3}$, and CVD was carried out under the same conditions as Figs. 3 and 4, using 1.1 vol\% $\mathrm{C}_{2} \mathrm{H}_{2}$ for either 10 or 20 min. The array lengths were measured for 10 arrays of each sample and the average value is plotted in $(k)$ with the maximum and minimum values as error bars. The weight of CNTs collected in one cycle of $\sim 1 \mathrm{~h}$ is shown in (1). 
3.4 Maintaining the activity of small catalyst particles by moderating $\mathrm{C}_{2} \mathrm{H}_{2}$ feed to produce sub-millimeter-long FWCNTs with reduced diameter and improved purity

Because small catalyst particles are more easily deactivated by $\mathrm{C}_{2} \mathrm{H}_{2}$ with high concentration [25,32], we reduced the $\mathrm{C}_{2} \mathrm{H}_{2}$ feeds to maintain the activity of the small $\mathrm{Fe}$ particles. Fig. 7a-h shows the SEM images of CNT forests collected in the container bottle. The CNTs were sub-millimeter-long and well-aligned for all the conditions considered: large and small Fe catalyst particles (250 and $50 \mathrm{~cm}^{3} \mathrm{Ar}$ carrier gas for ferrocene, respectively), 0.73 and 0.37 vol\% $\mathrm{C}_{2} \mathrm{H}_{2}$, and 10 and 20 min CVD. The amounts of CNTs are shown in the histograms for different $\mathrm{C}_{2} \mathrm{H}_{2}$ concentrations in Fig. 7i-k. With a high $\mathrm{C}_{2} \mathrm{H}_{2}$ concentration of 1.1 vol\% (Fig. 7i), increasing the CVD time from 10 to 20 min only increased the amount of CNTs for large Fe particles, meaning that the small catalyst particles were rapidly deactivated within about $10 \mathrm{~min}$. With a low $\mathrm{C}_{2} \mathrm{H}_{2}$ concentration of 0.37 vol\% (Fig. 7k), increasing the CVD time from 10 to 20 min resulted in an increased amount of CNTs for both large and small Fe particles, because of the increased lifetime of the small Fe particles. However, the significant decrease in the $\mathrm{C}_{2} \mathrm{H}_{2}$ concentration from 1.1 to 0.37 vol\% resulted in a significant decrease in the amount of CNTs collected, because of not only the decreased amount of synthesized CNTs but also the decreased separation efficiency of the short CNT arrays from the beads. The moderate $\mathrm{C}_{2} \mathrm{H}_{2}$ concentration of 0.73 vol\% (Fig. $7 \mathrm{j}$ ) resulted in an increased CNT amount with increasing CVD time from 10 to 20 min for both large and small $\mathrm{Fe}$ particles. In addition, the CNT arrays were sufficiently long to be well-separated after $20 \mathrm{~min}$ CVD for both the catalysts, resulting in more than twice the amount of CNTs collected than for 10 min CVD. The moderate $\mathrm{C}_{2} \mathrm{H}_{2}$ feed of 0.73 vol\% had the best balance between CNT growth rate and catalyst lifetime, and gave more CNTs $(0.62 \mathrm{~g}$, corresponding to a carbon yield of $42 \%)$ after $20 \mathrm{~min}$ with small Fe particles $\left(50 \mathrm{~cm}^{3} \mathrm{Ar}\right.$ gas for ferrocene) than the high $\mathrm{C}_{2} \mathrm{H}_{2}$ feed of 1.1 vol\% ( $0.45 \mathrm{~g}$, corresponding to a carbon yield of $\left.20 \%\right)$. 


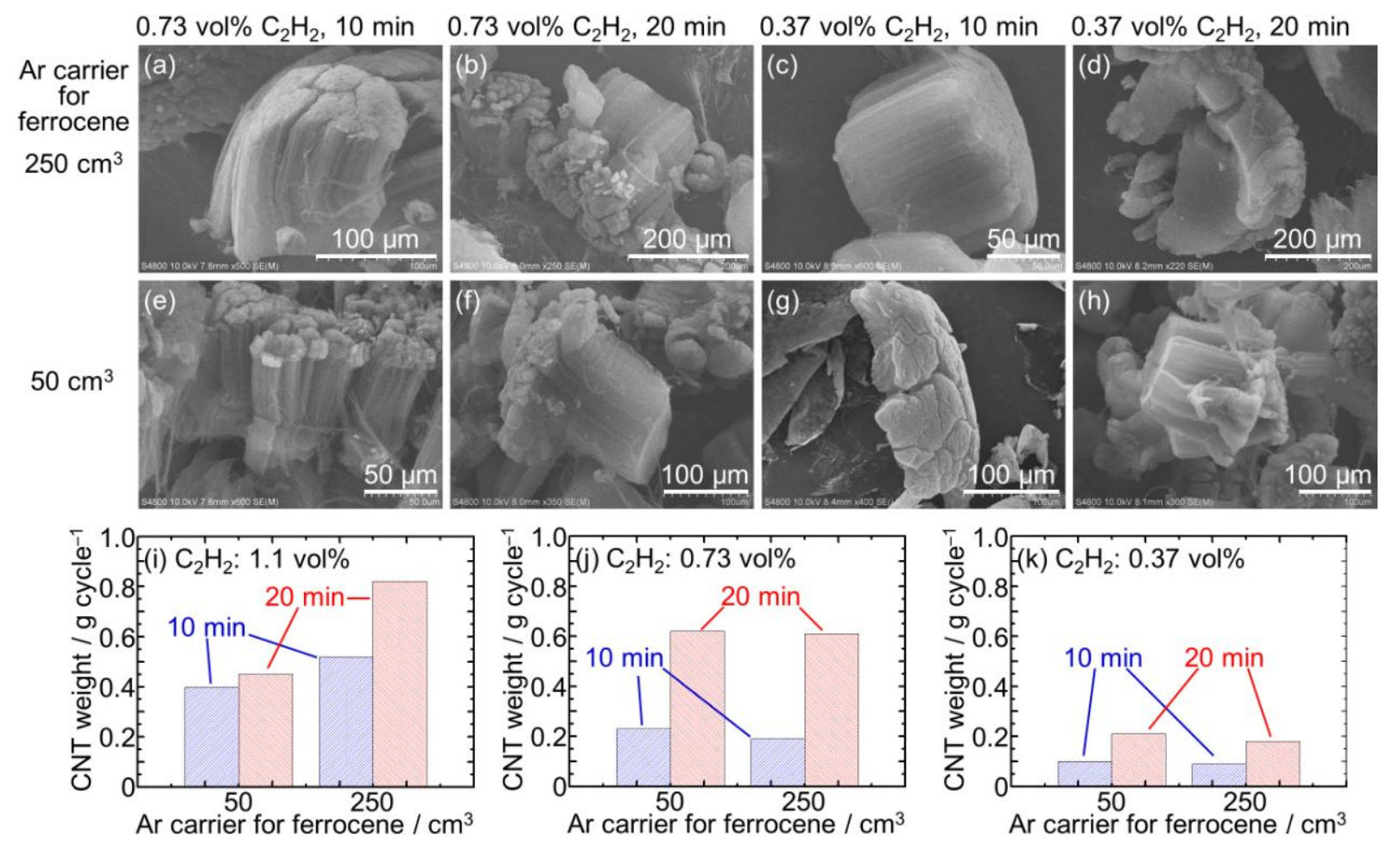

Fig. 7 - (a-h) SEM images and (i-k) weights of CNT arrays collected in the container bottle. The large and small Fe catalyst particles were prepared with (a-d) 250 and (e-h) 50 standard $\mathrm{cm}^{3}$ Ar carrier gas for ferrocene, respectively. The CNTs were synthesized by 10 min CVD for (a, c, e, g), and 20 min CVD for (b, d, f, h). The $\mathrm{C}_{2} \mathrm{H}_{2}$ concentrations were 0.73 vol\% for $(a, b, e, f)$, and 0.37 vol\% for $(c, d, g, h)$. The weights of CNTs obtained with $\mathrm{C}_{2} \mathrm{H}_{2}$ concentrations of (i) 1.1 (the same data as in Fig. 6), (j) 0.73, and (k) 0.37 vol\%

We then examined the diameter of the CNTs synthesized with the moderate $\mathrm{C}_{2} \mathrm{H}_{2}$ concentration of 0.73 vol\% by TEM (Fig. 8). The CNTs produced using small Fe particles (50 standard $\mathrm{cm}^{3}$ Ar gas for ferrocene) with 0.73 vol\% $\mathrm{C}_{2} \mathrm{H}_{2}$ (Fig. 8d-f) had smaller diameters, thinner walls, and cleaner surfaces than those produced using the large Fe particles (250 standard $\mathrm{cm}^{3} \mathrm{Ar}$ gas for ferrocene) with both 1.1 (Fig. 4d-f) and 0.73 vol\% (Fig. 8a-c) $\mathrm{C}_{2} \mathrm{H}_{2}$. The inset histograms of the CNT diameter distributions as well as the graph of the average diameter versus the depth from the top of the array (Fig. 8g) show that there was a gradual 
increase in diameter from the top to the bottom in both cases. The average diameter increased from 8.7 to $11.6 \mathrm{~nm}$ using the large Fe particles with an average diameter of $10.1 \mathrm{~nm}$, while it increased from 5.6 to $7.3 \mathrm{~nm}$ using the small Fe particles with an average diameter of $6.5 \mathrm{~nm}$. Because CNTs grow via the root growth mode, the diameter of CNTs increased with time during CVD. Although the CNTs increased in diameter regardless of the Ar carrier gas volume for ferrocene, and thus the Fe particle size, CNTs with smaller diameters nucleated and grew from the smaller catalyst particles, and retained their smaller diameters when CVD was performed at a moderate carbon feed of 0.73 vol\% $\mathrm{C}_{2} \mathrm{H}_{2}$. The $\mathrm{N}_{2}$ adsorption measurement (Figs. S2, S3) at $77 \mathrm{~K}$ showed that the CNTs had a BET specific surface area of $440 \mathrm{~m}^{2} \mathrm{~g}^{-1}$ for the CNTs synthesized with the small Fe particles and moderate $\mathrm{C}_{2} \mathrm{H}_{2}$ feed of 0.73 vol\% (Fig. $\mathrm{S} 3$ ), while it was $367 \mathrm{~m}^{2} \mathrm{~g}^{-1}$ for the large Fe particles and high $\mathrm{C}_{2} \mathrm{H}_{2}$ feed of 1.1 vol\% (Fig. S2). The value of $440 \mathrm{~m}^{2} \mathrm{~g}^{-1}$ is about one-sixth of the theoretical value for monolayer graphene $\left(2730 \mathrm{~m}^{2} \mathrm{~g}^{-1}\right)$, and thus about one-third of that of SWCNTs with closed ends $[35,36]$. This result indicates that the average number of walls of the synthesized CNTs was three for the small Fe particles $\left(50 \mathrm{~cm}^{3}\right.$ Ar gas for ferrocene) with the moderate carbon feed $(0.73 \mathrm{vol} \%$ $\mathrm{C}_{2} \mathrm{H}_{2}$ ). 

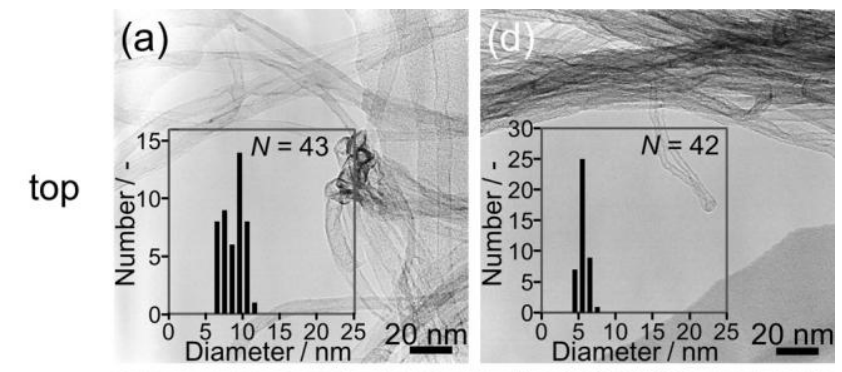

(b)
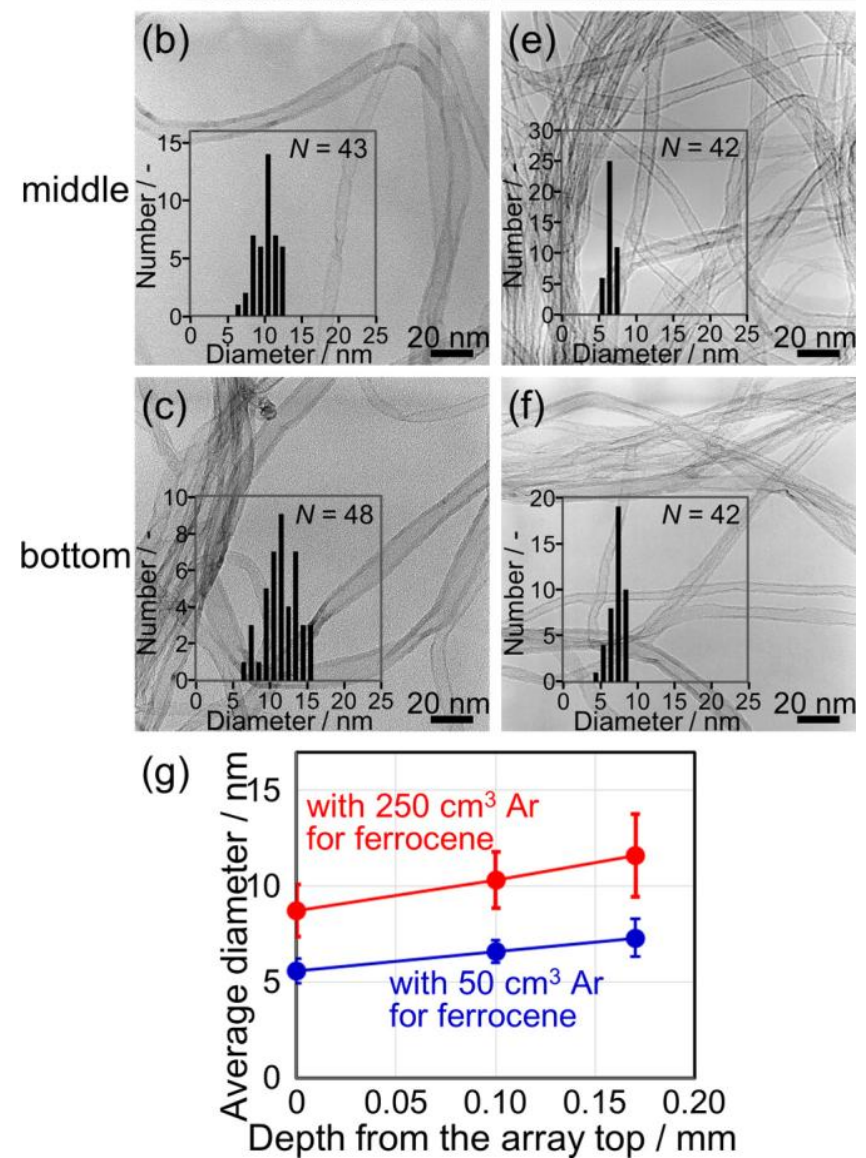

Fig. 8 - TEM images and diameter distributions of CNTs synthesized with 0.73 vol\% $\mathrm{C}_{2} \mathrm{H}_{2}$ for large and small Fe catalyst particles prepared with (a-c) 250 and (d-f) 50 standard $\mathrm{cm}^{3}$ Ar carrier gas for ferrocene, respectively: (a, d) top, (b, e) middle, and (c, f) bottom of a single piece of CNTs taken out of the array. In (g), the changes in the average diameter of the CNTs with $250 \mathrm{~cm}^{3}$ and $50 \mathrm{~cm}^{3} \mathrm{Ar}$ carrier gas for ferrocene are plotted against the depth from the top of the CNT arrays. The error bars show the standard deviation.

We analyzed the purity of CNTs synthesized with small Fe particles $\left(50 \mathrm{~cm}^{3}\right.$ Ar gas for 
ferrocene $)$ and moderate carbon feed $\left(0.73\right.$ vol $\left.\% \mathrm{C}_{2} \mathrm{H}_{2}\right)$ by XRF and TG-DTA. We prepared two CNT papers for analysis by XRF. One paper is prepared by dispersing CNT powders (3 $\mathrm{mg}$ ) in ethanol $(30 \mathrm{~mL})$ by ultrasonication $(3 \mathrm{~min})$ and filtrating all of the dispersion. The other is prepared by dispersing CNT powders (4 mg) with sodium dodecylbenzenesulfonate surfactant (SDBS, $50 \mathrm{mg}$ ) in water $(40 \mathrm{~mL})$ by ultrasonication $(3 \mathrm{~min})$, centrifuging the dispersion mildly (3000 rpm, $10 \mathrm{~min}$ ), and then filtrating the supernatant. Note that no other purification, such as acid treatment, was applied in making these papers. Table 1 shows the elemental composition of these papers. The paper prepared by filtrating all dispersion without centrifugation (and thus without any purification) had a high carbon purity of $99.8 \mathrm{wt} \%$. Such high purity is sometimes reported for SWCNT arrays synthesized on flat substrates [22] but not for FBCVD. The other paper prepared by filtrating the supernatant after a mild centrifugation showed even smaller contaminations of $\mathrm{Al}$ and $\mathrm{Fe}(1 / 6-1 / 7$ of the paper without centrifugation). These $\mathrm{Fe}$ and $\mathrm{Al}$ contaminations should be contained mainly as powders just mixing with CNTs, which are easily separated from the CNT dispersion by settling during centrifugation. Note that if these catalyst impurities are encapsulated by CNTs, they cannot be removed just by dispersion and centrifugation. The TG-DTA result shows that the as-synthesized CNT powder had a carbon purity of $99.6 \mathrm{wt} \%$ with amorphous carbon of $\sim 2 \mathrm{wt} \%$ and a high oxidation stability of $\sim 650{ }^{\circ} \mathrm{C}$ (Fig. 9a). We analyzed the compositions of the ash after TG-DTA by EDX (Fig. 9b). The ash contained Fe and Al, which are attributed mainly to the $\mathrm{Fe}$ catalyst and $\mathrm{AlO}_{x}$ support layer being scraped off during the vigorous fluidization for CNT separation. The small Si content can be attributed to the reactor tube made of quartz glass being slightly scraped off. The weight of the ash was $0.05 \mathrm{mg}$, which is in good agreement with the $0.4 \mathrm{wt} \%$ impurity in the $10.2 \mathrm{mg}$ CNTs used for the TG-DTA measurement when we take into account the weight increase from $0.019 \mathrm{mg}$ Fe in the CNT powder to $0.027 \mathrm{mg} \mathrm{Fe}_{2} \mathrm{O}_{3}$ in the ash. There was a slight deviation in the carbon purity and 
$\mathrm{Fe} / \mathrm{Al}$ ratio between the two measurements (XRF in Table 1 and TG-DTA with SEM-EDS in Fig. 9). However, it is clear that the CNTs synthesized by our FBCVD method with careful control of the catalyst and carbon feeds gave 99.6-99.8 wt\%-pure sub-millimeter-long CNT arrays, and that the small catalyst contamination can be reduced further easily by dispersion and centrifugation. Such pure and long CNTs are attractive especially for use as electrodes and 3D current collectors in secondary batteries [37] and electrochemical capacitors [38].

\begin{tabular}{lcccccc}
\multicolumn{6}{l}{ Table 1 - Elemental composition of the CNT papers* by XRF } \\
\begin{tabular}{lcccccc} 
Element & C & O & Al & Si & Fe \\
\hline without centrifugation & 99.81 & 0.10 & 0.06 & 0.01 & 0.02 \\
with centrifugation** & 99.84 & 0.14 & 0.01 & 0.01 & 0.003
\end{tabular}
\end{tabular}

*No chemical purification was applied in making the CNT papers. $* * \mathrm{~S}$ is also contained at $0.61 \mathrm{wt} \%$ due to SDBS used in dispersion.
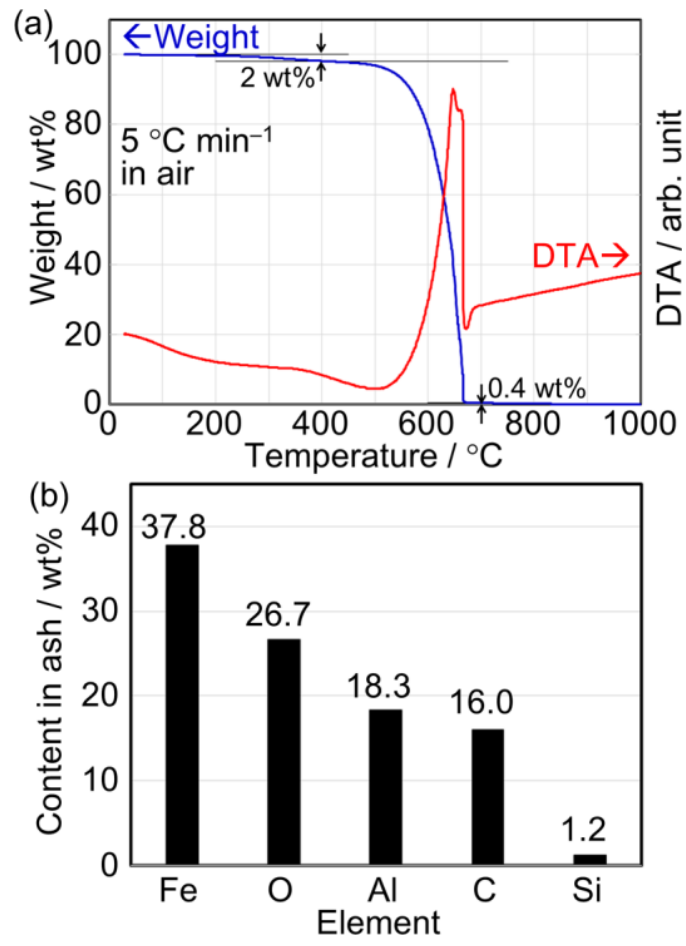

Fig. 9 - (a) TG-DTA curves of the CNTs synthesized using small Fe particles $\left(50 \mathrm{~cm}^{3} \mathrm{Ar}\right.$ carrier gas for ferrocene) with 0.73 vol\% $\mathrm{C}_{2} \mathrm{H}_{2}$. The sample was the same as that in Fig. 8d-f. (b) Elemental composition of the ash after the TG-DTA measurement. 
We analyzed the composition of the carbon-containing species in the effluent gas from the FBCVD reactor by GC-FID at 2 min intervals for 20 min CVD (Fig. 10). We first supplied the CVD gas to the tube filled with pristine beads at room temperature (r. t.) to eliminate the influence of the catalytic reaction, and used this data as the reference. For the effluent gas during CVD, $\mathrm{CH}_{4}, \mathrm{C}_{2} \mathrm{H}_{2}, \mathrm{CO}_{2}$ and $\mathrm{C}_{2} \mathrm{H}_{4}$ were the main carbon-containing species. Small peaks for $\mathrm{C}_{2} \mathrm{H}_{6}$ and $\mathrm{CO}$ were also detected. The concentrations of $\mathrm{CO}_{2}$ and $\mathrm{CO}$ were around 0.1 and 0.03 vol\%, respectively, which are somewhat higher than the expected values from the 0.06 vol\% $\mathrm{H}_{2} \mathrm{O}$ feed, presumably because of some species desorbing from the beads, gas-lines, and/or the reactor walls. There were two stages of CNT growth: an early stage from 0 to $10 \mathrm{~min}$, where the conversion of $\mathrm{C}_{2} \mathrm{H}_{2}$ to undetectable carbon (mostly CNTs) was as high as $70-80 \%$; and a later stage from 10 to $20 \mathrm{~min}$, where the catalyst gradually deactivated and the conversion decreased to $40-70 \%$. The total conversion was around $60 \%$. There was a deviation in the conversion of $\mathrm{C}_{2} \mathrm{H}_{2}$ to undetectable carbon ( $60 \%$ by GC) and the carbon yield of CNTs (42\% from the weight of collected CNTs). To clarify the reason, we analyzed the CNT arrays on beads without separating them by the gas flow (Fig. S4). Both the pristine beads and the beads with CNTs had certain distributions in radius. The CNT arrays on beads also had a certain distribution in height and were shorter on the beads (Fig. S4d) than in the container bottle (Fig. 6k). The catalyst line directly feeding the catalyst vapors to the center of the bed (Fig. S1) prevented the stacking of the distributor while caused some distribution in the catalyst thickness among different beads, resulting in the distribution in the CNT array height. It is probable that long CNT arrays were separated from the beads while the short CNT arrays remained on the beads, resulting in the smaller CNT yield than the $\mathrm{C}_{2} \mathrm{H}_{2}$ conversion. Development of a more efficient separation method is currently underway. 


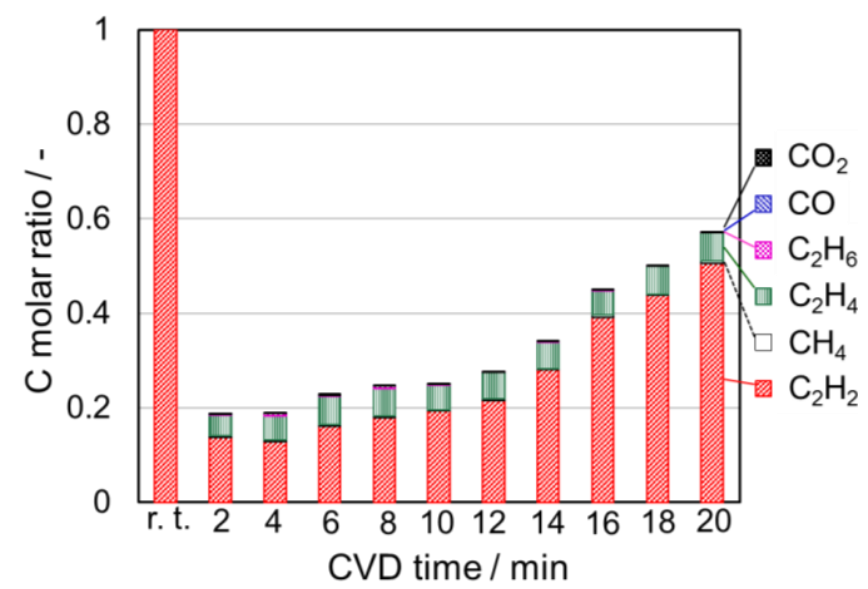

Fig. 10 - Composition of the effluent gas from the FBCVD reactor for different CVD times analyzed by gas chromatography. CVD was carried out with the moderate carbon feed of 0.73 vol\% $\mathrm{C}_{2} \mathrm{H}_{2}$ and the small Fe particles with $50 \mathrm{~cm}^{3} \mathrm{Ar}$ carrier gas for ferrocene.

\section{Conclusions}

In this study, we proposed and developed a new FBCVD reactor with internal heat-exchanger and preheater with the aim of efficiently synthesizing CNTs with controlled structure. The new heater realized uniform heating of the bed even for a space velocity as high as $3600 \mathrm{~h}^{-1}$ (corresponding to a gas residence time $<0.3 \mathrm{~s}$ at $745^{\circ} \mathrm{C}$ ) and direct feeding of cold catalyst vapor source into the bed. Using this new reactor, sub-millimeter-long CNTs were semi-continuously produced from $\mathrm{C}_{2} \mathrm{H}_{2}$ using a Fe/ $\mathrm{AlO}_{x}$ catalyst at $745^{\circ} \mathrm{C}$ with careful control of the structures of the catalyst and CNTs. The nominal thickness and size of the catalyst Fe particles could be easily controlled by the amount of ferrocene feed, whereas it was difficult to control the number density of the Fe particles, which remained at around $10^{10}-10^{11} \mathrm{~cm}^{-2}$ (one order of magnitude smaller than those prepared on flat substrates by sputtering). With a high $\mathrm{C}_{2} \mathrm{H}_{2}$ feed $\left(1.1 \mathrm{vol} \% \mathrm{C}_{2} \mathrm{H}_{2}\right)$, the weight of produced CNTs remained almost constant for different $\mathrm{Fe}$ catalysts for a short reaction time (10 min), whereas the small 
Fe particles were easily deactivated within 10 min. A moderate $\mathrm{C}_{2} \mathrm{H}_{2}$ feed $(0.73$ vol\%) increased the catalyst lifetime to $\sim 20 \mathrm{~min}$ and realized the efficient production (carbon yield $>40$ at $\%$ ) of small diameter FWCNTs (6.5 nm on average) at a purity of 99.6-99.8 wt\%. This semi-continuous FBCVD process with careful control of the CNT structure can be used to produce CNTs for various practical applications, including electrodes for electric storage devices.

\section{Acknowledgments}

The authors thank Mr. T. Ito for assistance in the TEM observations and Prof. Kuroda, Prof. Shimojima, and Mr. Yamamoto for their support with the BET measurements. This work was financially supported by ALCA from JST, Japan, Grant-in-Aid for Scientific Research (A) (No. 25249111) from MEXT, Japan, and by Hitachi Chemical Co. Ltd. The TEM observations were conducted at the Center for Nano Lithography and Analysis, The University of Tokyo. Z. C. was supported by the Scholarship under the State Scholarship Fund by the China Scholarship Council (CSC). 


\section{REFERENCES}

[1] Reddy ALM, Shaijumon MM, Gowda SR, Ajayan PM. Coaxial $\mathrm{MnO}_{2}$ /carbon nanotube array electrodes for high-performance lithium batteries. Nano Lett 2009;9(3):1002-6.

[2] Jiang Y, Wang P, Zang X, Yang Y, Kozinda A, Lin L. Uniformly embedded metal oxide nanoparticles in vertically aligned carbon nanotube forests as pseudocapacitor electrodes for enhanced energy storage. Nano Lett 2013;13(8):3524-30.

[3] Phillips AB, Khanal RR, Song Z, Zartman RM, DeWitt JL, Stone JM, et al. Wiring-up carbon single wall nanotubes to polycrystalline inorganic semiconductor thin films: low-barrier, copper-free back contact to CdTe solar cells. Nano Lett 2013;13(11):5224-32.

[4] Zou Y, Li Q, Liu J, Jin Y, Qian Q, Jiang K, et al. Fabrication of all-carbon nanotube electronic devices on flexible substrates through CVD and transfer methods. Adv Mater 2013;25(42):6050-6.

[5] Fu K, Yildiz O, Bhanushali H, Wang Y, Stano K, Xue L, et al. Aligned carbon nanotube-silicon sheets: a novel nano-architecture for flexible lithium ion battery electrodes. Adv Mater 2013;25(36):5109-14.

[6] You B, Li N, Zhu H, Zhu X, Yang J. Graphene oxide-dispersed pristine CNTs support for $\mathrm{MnO}_{2}$ nanorods as high performance supercapacitor electrodes. ChemSusChem 2013;6(3):474-80.

[7] Tans SJ, Devoret MH, Dai H, Thess A, Smalley RE, Geerligs LJ, et al. Individual single wall carbon nanotubes as quantum wires. Nature 1997;386(6624):474-7.

[8] Javey A, Guo J, Wang Q, Lundstrom M, Dai H. Ballistic carbon nanotube field-effect transistors. Nature 2003;424(0):654-7.

[9] Thess A, Lee R, Nikolaev P, Dai H, Petit P, Robert J, et al. Crystalline ropes of metallic 
carbon nanotubes. Science 1996;273(5274):483-7.

[10] Nikolaev P, Bronikowski MJ, Bradley RK, Rohmund F, Colbert DT, Smith KA, et al. Gas-phase catalytic growth of single-walled carbon nanotubes from carbon monoxide. Chem Phys Lett 1999;313(1):91-7.

[11] Jeong HJ, Kim KK, Jeong SY, Park MH, Yang CW, Lee YH. High-yield catalytic synthesis of thin multiwalled carbon nanotubes. J Phys Chem B 2004;108(46):17695-8.

[12] Endo M, Muramatsu H, Hayashi T, Kim YA, Terrones M, Dresselhaus MS. 'Buckypaper' from coaxial nanotubes. Nature 2005,433(7025):476.

[13] Hofmann S, Ducati C, Robertson J, Kleinsorge B. Low-temperature growth of carbon nanotubes by plasma-enhanced chemical vapor deposition. Appl Phys Lett 2003;83(1):135-7.

[14] Zhang Q, Huang J-Q, Zhao M-Q, Qian W-Z, Wei F. Carbon nanotube mass production: principles and processes. ChemSusChem 2011;4(7):864-89.

[15] Mleczko L, Lolli G. Carbon nanotubes: an example of multiscale development-a mechanistic view from the subnanometer to the meter scale. Angew Chem Int Ed 2013;52(36):9372-87.

[16] Philippe R, Morançais A, Corrias M, Caussat B, Kihn Y, Kalck P, et al. Catalytic production of carbon nanotubes by fluidized-bed CVD. Chem Vapor Depos 2007;13(9):447-57.

[17] See $\mathrm{CH}$, Harris AT, A review of carbon nanotube synthesis via fluidized-bed chemical vapor deposition. Ind Eng Chem Res 2007;46(4):997-1012.

[18] Zhang Q, Zhao M, Huang J, Nie J, Wei F. Mass production of aligned carbon nanotube arrays by fluidized bed catalytic chemical vapor deposition. Carbon 2010,48(4):1196-209.

[19] Kim DY, Sugime H, Hasegawa K, Osawa T, Noda S. Sub-millimeter-long carbon 
nanotubes repeatedly grown on and separated from ceramic beads in a single fluidized bed reactor. Carbon 2011;49(6):1972-9.

[20] Kim DY, Sugime H, Hasegawa K, Osawa T, Noda S. Fluidized-bed synthesis of sub-millimeter-long single walled carbon nanotube arrays. Carbon 2012;50(4):1538-45.

[21] Li WZ, Xie SS, Qian LX, Chang BH, Zou BS, Zhou WY, et al. Large-scale synthesis of aligned carbon nanotubes. Science 1996;274(5293):1701-3.

[22] Hata K, Futaba DN, Mizuno K, Namai T, Yumura M, Iijima S. Water-assisted highly efficient synthesis of impurity-free single-walled carbon nanotubes. Science 2004;306(5700):1362-4.

[23] Noda S, Hasegawa K, Sugime H, Kakehi K, Zhang Z, Maruyama S, et al. Millimeter-thick single-walled carbon nanotube forests: hidden role of catalyst support. Jpn J Appl Phys 2007;46(17):399-401.

[24] Sugime H, Noda S. Millimeter-tall single-walled carbon nanotube forests grown from ethanol. Carbon 2010;48(8):2203-11.

[25] Hasegawa K, Noda S. Millimeter-tall single-walled carbon nanotubes rapidly grown with and without water. ACS Nano 2011;5(2):975-84.

[26] Chen Z, Kim DY, Hasegawa K, Noda S. Methane-assisted ahemical vapor deposition yielding millimeter-tall single-wall carbon nanotubes of smaller diameter. ACS Nano 2013;7(8):6719-28.

[27] Xiang R, Luo G, Qian W, Wang Y, Wei F, Li Q. Large area growth of aligned CNT arrays on spheres: towards large scale and continuous production. Chem Vapor Depos 2007;13(10):533-6.

[28] Zhang Q, Huang J, Zhao M, Qian W, Wang Y, Wei F. Radial growth of vertically aligned carbon nanotube arrays from ethylene on ceramic spheres. Carbon 2008;46(8):1152-8. 
[29] Xiang R, Luo G, Yang Z, Zhang Q, Qian W, Wei F. Large area growth of aligned CNT arrays on spheres: cost performance and product control. Mater Lett 2009;63(1):84-7.

[30] Zhang Q, Zhao M, Huang J, Liu Y, Wang Y, Qian W, et al. Vertically aligned carbon nanotube arrays grown on a lamellar catalyst by fluidized bed catalytic chemical vapor deposition. Carbon 2009;47(11):2600-10.

[31] Hasegawa K, Noda S. Diameter increase in millimeter-tall vertically aligned single-walled carbon nanotubes during growth. Appl Phys Express 2010;3(4):045103-1-3.

[32] Hasegawa K, Noda S. Moderating carbon supply and suppressing Ostwald ripening of catalyst particles to produce 4.5 -mm-tall single-walled carbon nanotube forests. Carbon 2011;49(13):4497-504.

[33] Xiang R, Einarsson E, Murakami Y, Shiomi J, Chiashi S, Tang Z, et al. Diameter modulation of vertically aligned single-walled carbon nanotubes. ACS Nano 2012;6(8):7472-9.

[34] Kakehi K, Noda S, Maruyama S, Yamaguchi Y. Growth valley dividing single- and multi-walled carbon nanotubes: combinatorial study of nominal thickness of Co catalyst. Jpn J Appl Phys 2008;47(4):1961-1965.

[35] Hiraoka T, Izadi-Najafabadi A, Yamada T, Futaba DN, Yasuda S, Tanaike O, et al. Compact and light supercapacitor electrodes from a surface-only solid by opened carbon nanotubes with $2200 \mathrm{~m}^{2} \mathrm{~g}^{-1}$ surface area. Adv Fun Mater 2010;20(3):422-8.

[36] Peigney A, Laurent C, Flahaut E, Bacsa RR, Rousset A. Specific surface area of carbon nanotubes and bundles of carbon nanotubes. Carbon 2001;39(4):507-14.

[37] Lee SW, Gallant BM, Lee Y, Yoshida N, Kim DY, Yamada Y, et al. Self-standing positive electrodes of oxidized few-walled carbon nanotubes for light-weight and high-power lithium batteries. Energy Environ Sci 2012;5(1):5437-44. 
[38] Quintero R, Kim DY, Hasegawa K, Yamada Y, Yamada A, Noda S. Carbon nanotube 3D current collectors for lightweight, high performance and low cost supercapacitor electrodes. RSC Adv 2014;4(16):8230-37. 


\section{Captions}

Table 1 - Elemental composition of the CNT papers* by XRF

Fig. 1 - Schematics of the semi-continuous fluidized-bed process: (a) deposition of $\mathrm{AlO}_{x}$ support layer from aluminum-isopropoxide followed by deposition of Fe catalyst particles from ferrocene; (b) reduction of Fe catalyst by introducing $\mathrm{H}_{2}$ followed by CNT growth by feeding $\mathrm{C}_{2} \mathrm{H}_{2}$; and (c) separation of CNTs from beads by increasing $\mathrm{Ar}$ gas flow. After removing the residual carbon on the beads by introducing $\mathrm{O}_{2}$, the next cycle is carried out starting at step (a). The whole process can be repeated by just changing the gas flow while keeping the bed heated at a fixed temperature for tens of cycles without changing the beads.

Fig. 2 - Schematics of (a) the old single tube and (b) the new coaxial double tube with temperature distributions for various Ar gas feeds. In (a), Ar gas was fed at 3.16-10 slm to the bed through the distributor at the bottom. In (b), Ar gas was fed through two inlets: constantly from the catalyst line at the bottom at $1 \mathrm{slm}$ and from the top through the heat-exchange and preheating zone and the distributor at the bottom at 4-29 slm. The inner tube diameter for the bed was $22 \mathrm{~mm}$ for (a) and $40 \mathrm{~mm}$ for (b), and the set temperature was $820^{\circ} \mathrm{C}$ for both (a) and (b).

Fig. 3 - Photos of the fluidized-bed reactor taken by stopping the gas flow and interrupting the cycle at each step of the semi-continuous operation: (a) the bed with pristine beads before CVD; (b) the bead bed after CVD; (c) the bead bed after CNT separation; and (d) CNTs collected in a $0.5 \mathrm{~L}$ container in one cycle. All steps were performed by gas flow modulation at a fixed set temperature of $745^{\circ} \mathrm{C}$ in a single fluidized-bed reactor. 
Fig. 4 - (a, b) SEM images of the CNTs separated from the beads by the gas flow and collected in the container bottle. (c) The change in the average diameter of the CNTs plotted against the depth from the top of the CNT arrays. The error bars show the standard deviation. (d-f) TEM images and diameter distributions of CNTs at the top, middle, and bottom of a single piece of the CNTs taken out from the array, respectively.

Fig. 5 - (a) Relationship between the nominal Fe thickness and the Ar carrier gas volume for ferrocene. AFM images of the alumina bead surface with different catalyst layers: (b) $\mathrm{AlO}_{x}$, (c) $1.77 \mathrm{~nm} \mathrm{Fe}$ on $\mathrm{AlO}_{x}$, and (d) $0.28 \mathrm{~nm} \mathrm{Fe}$ in $\mathrm{AlO}_{x}$. The $\mathrm{AlO}_{x}$ layer was deposited by carrying aluminum isopropoxide using 450 standard $\mathrm{cm}^{3} \mathrm{Ar}$ gas in all cases. The Fe catalyst was deposited on the $\mathrm{AlO}_{x}$ layer by carrying ferrocene using (c) 250 and (d) 50 standard $\mathrm{cm}^{3}$ Ar gas and reduced with $26 \mathrm{vol} \% \mathrm{H}_{2} / 0.06 \mathrm{vol} \% \mathrm{H}_{2} \mathrm{O} / \mathrm{Ar}$ at $9.48 \mathrm{slm}$ for $10 \mathrm{~min}$.

Fig. $6-(a-j)$ SEM images, (k) array lengths, and (l) weight of CNT arrays collected in the container bottle. The Ar carrier gas for ferrocene was varied between 50 and 250 standard $\mathrm{cm}^{3}$, and CVD was carried out under the same conditions as Figs. 3 and 4 , using 1.1 vol $\% \mathrm{C}_{2} \mathrm{H}_{2}$ for either 10 or $20 \mathrm{~min}$. The array lengths were measured for 10 arrays of each sample and the average value is plotted in $(\mathrm{k})$ with the maximum and minimum values as error bars. The weight of CNTs collected in one cycle of $\sim 1 \mathrm{~h}$ is shown in (l).

Fig. 7 - (a-h) SEM images and (i-k) weights of CNT arrays collected in the container bottle. The large and small Fe catalyst particles were prepared with (a-d) 250 and (e-h) 50 standard $\mathrm{cm}^{3} \mathrm{Ar}$ carrier gas for ferrocene, respectively. The CNTs were synthesized by 10 min CVD for (a, c, e, g), and 20 min CVD for (b, d, f, h). The $\mathrm{C}_{2} \mathrm{H}_{2}$ concentrations were 0.73 vol\% for (a, b, 
e, f), and 0.37 vol\% for (c, d, g, h). The weights of CNTs obtained with $\mathrm{C}_{2} \mathrm{H}_{2}$ concentrations of (i) 1.1 (the same data as in Fig. 6), (j) 0.73, and (k) 0.37 vol\%.

Fig. 8 - TEM images and diameter distributions of CNTs synthesized with 0.73 vol\% $\mathrm{C}_{2} \mathrm{H}_{2}$ for large and small Fe catalyst particles prepared with (a-c) 250 and (d-f) 50 standard $\mathrm{cm}^{3} \mathrm{Ar}$ carrier gas for ferrocene, respectively: $(\mathrm{a}, \mathrm{d})$ top, $(\mathrm{b}, \mathrm{e})$ middle, and $(\mathrm{c}, \mathrm{f})$ bottom of a single piece of CNTs taken out of the array. In (g), the changes in the average diameter of the CNTs with $250 \mathrm{~cm}^{3}$ and $50 \mathrm{~cm}^{3}$ Ar carrier gas for ferrocene are plotted against the depth from the top of the CNT arrays. The error bars show the standard deviation.

Fig. 9 - (a) TG-DTA curves of the CNTs synthesized using small Fe particles $\left(50 \mathrm{~cm}^{3} \mathrm{Ar}\right.$ carrier gas for ferrocene) with 0.73 vol\% $\mathrm{C}_{2} \mathrm{H}_{2}$. The sample was the same as that in Fig. 8d-f. (b) Elemental composition of the ash after the TG-DTA measurement.

Fig. 10 - Composition of the effluent gas from the FBCVD reactor for different CVD times analyzed by gas chromatography. CVD was carried out with the moderate carbon feed of 0.73 vol\% $\mathrm{C}_{2} \mathrm{H}_{2}$ and the small Fe particles with $50 \mathrm{~cm}^{3}$ Ar carrier gas for ferrocene. 